\title{
Calciphylaxis presenting in early chronic kidney disease with mixed hyperparathyroidism
}

This article was published in the following Dove Press journal: International Journal of Nephrology and Renovascular Disease 16 December 2011

Number of times this article has been viewed

\author{
Michael Brucculeri ${ }^{1,2}$ \\ Allan H Haydon ${ }^{2}$ \\ 'Renal Hypertension Center, Hudson, \\ FL, ${ }^{2}$ Morton Plant Hospital, University \\ of South Florida College of Medicine, \\ Clearwater, FL, USA
}

\begin{abstract}
Calciphylaxis is a disabling and life-threatening complication that primarily affects patients who are dialysis dependent. Reports have grown in the literature of cases occurring in those who have advanced chronic kidney disease (pre-end-stage renal disease) or in the setting of transplantation. There are also a few reports of cases occurring in those without any form of chronic kidney disease but with primary hyperparathyroidism. This disease entity is characterized by calcification, intimal hypertrophy, and thrombosis of small vessels that result in necrotizing, nonhealing ulcers - many of which are life threatening. Although several strategies aimed at treating and preventing this affliction have been reported in the literature, the outcome for most patients with calciphylaxis remains quite poor. We describe a patient with comparatively early stage-3 chronic kidney disease who developed calciphylaxis in the setting of both primary and secondary hyperparathyroidism. Predictably, after subtotal parathyroidectomy, her wounds did not completely heal and her biochemical markers of hyperparathyroidism did not completely normalize until her underlying secondary hyperparathyroidism was treated medically. It was only after initiating cinacalcet that the patient experienced complete wound healing and resolution of her calciphylaxis. It also supports other authors' findings that cinacalcet may be an important adjunct in the treatment of calciphylaxis.
\end{abstract}

Keywords: calciphylaxis, chronic kidney disease, cinacalcet, parathyroidectomy

\section{Case report}

A 66-year-old Caucasian woman with a medical history significant for chronic kidney disease (CKD) stage 3, hypertension, and morbid obesity was followed regularly at our nephrology and hypertension clinic. She was being treated aggressively for her hypertension, proteinuria, hyperuricemia, and secondary hyperparathyroidism (SHPT). Her baseline creatinine fluctuated between $1.5 \mathrm{mg} / \mathrm{dL}$ and $2.0 \mathrm{mg} / \mathrm{dL}$, and eGFR (6 variable Modification of Diet in Renal Disease) between 24 and $34 \mathrm{~mL} / \mathrm{min} / 1.73 \mathrm{~m}^{2}$. Her home medications included paricalcitol, gemfibrozil, febuxostat, pantoprazole, furosemide, lisinopril, latanoprost ophthalmic, and ferrous sulfate. Our patient had never taken warfarin, vitamin D, or any oral phosphate binders. In 2009, her intact parathyroid hormone (PTH) levels were noted to be rising despite her receiving oral paricalcitol $1 \mathrm{mcg}$ daily. The dose was eventually adjusted up to $2 \mathrm{mcg}$ daily without controlling her PTH which climbed as high as $216 \mathrm{pg} / \mathrm{mL}$. Her calcium levels climbed from 9.0 to $10.4 \mathrm{mg} / \mathrm{dL}$ but never higher. Her serum phosphorous levels ranged from 2.9 to $3.7 \mathrm{mg} / \mathrm{dL}$ before, during, and after subsequent treatment. Most importantly, the $\mathrm{Ca}^{2+} \times \mathrm{PO}_{4}{ }^{2-}$ solubility product was never greater than 33.7. In August 2010, she presented with painful eruptions and ulcerations along the medial aspects of her thighs
Correspondence: Michael J Brucculeri Section of Nephrology, Morton Plant Hospital, I I 24 Lakeview Road, Clearwater, FL 33756, USA

$\mathrm{Tel}+\mathrm{I} 7274426245$

$\mathrm{Fax}+\mathrm{I} 7274473793$

Email mjb69@columbia.edu 
and intertriginous spaces of the lower extremities, slightly more on her right side. Initially, our patient was concerned that it represented a drug-related exanthem in response to a newly initiated uric acid-lowering agent. Accordingly, she had tried to self-medicate using over-the-counter preparations without success. Eventually she sought medical attention.

On exam, the presence of violaceous ulcerations were identified along the aforementioned distributions, some of which had already begun to drain purulent material. She was prescribed oral doxycycline as well as Cleocin-T gel and cultures and biopsy were procured while at the dermatology clinic. The patient was not noted to have had any substantial changes in her weight. An extensive hypercoagulable workup was negative, as was the presence of antiphospholipid antibodies. Complement levels were normal but serum protein electrophoresis found elevation of acute phase reactants suggesting acute inflammation. Cultures were unrevealing, however, the biopsy from the right medial thigh lesion revealed dermal necrosis with severe neutrophilic inflammation of the local blood vessels. The biopsy was nonspecific as calcium deposition was not identified, but the clinical picture was strongly suggestive of calciphylaxis. A repeat biopsy was not obtained due to our fear of inciting another ulcerating lesion. Furthermore, it has been shown that dermatopathology is most often nonspecific and often needs to be repeated several times to see the typical microvascular calcifications associated with calciphylaxis. ${ }^{1}$ For this reason, our nephrology clinic generally does not recommend biopsy of these ulcers.

At this point she was sent for a three-phase technetium bone scan that was markedly abnormal on blood pool imaging (Figure 1). It demonstrated widespread hyperintensities in the soft tissue of her thighs bilaterally corresponding to the suspect lesions, once again more so on her right side. The use of this imaging modality in calciphylaxis has been reported numerous times and has been shown to be abnormal with soft tissue uptake in up to $97 \%$ of patients with calciphylaxis, whether ulcerating or not. ${ }^{1,2}$ As such, she was referred for a technetium sestamibi parathyroid scan, which was suspicious for a parathyroid adenoma on the lower pole of the left lobe of the thyroid. This scan was repeated and confirmed by our surgeon who then performed a subtotal parathyroidectomy the following day. Intraoperatively, an enlarged parathyroid gland was identified, corresponding to the abnormality seen on imaging. It was later confirmed to be a hyperplastic parathyroid adenoma by pathology.

In the weeks following surgery, the drainage from her wounds begun to wane, margins began to heal, and her PTH

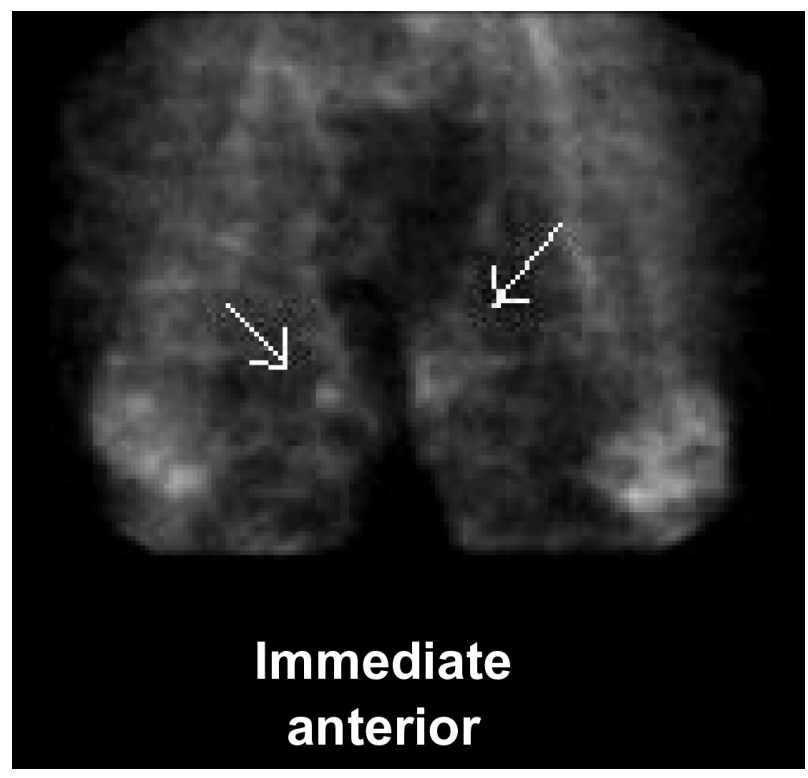

Figure I White arrows indicate areas of amorphous hyperintensity seen in the soft tissue on blood pool imaging of the 3-phase bone scan. They correspond to the patient's calciphylactic ulcers.

level fell to $136 \mathrm{pg} / \mathrm{mL}$, though did not fall lower on serial follow-up. It was at this point that her primary hyperparathyroidism was consider to have been definitively been treated, but the patient's "background" SHPT had not. We were reluctant to give her oral vitamin $\mathrm{D}$, or vitamin $\mathrm{D}$ receptor antagonists; instead, she was given cinacalcet. Within 3 months, her PTH had fallen to $38 \mathrm{pg} / \mathrm{mL}$ and her wounds had entirely healed.

Administration of the cinacalcet was not associated with hypocalcemia or significant change to our patient's $\mathrm{Ca}^{2+} \times \mathrm{PO}_{4}^{2-}$ solubility product, which was low to begin with.

\section{Discussion}

Calciphylaxis (often referred to as calcific uremic arteriolopathy) is a disabling, and potentially life-threatening complication that has been reported to affect as many as $4 \%$ of patients with end-stage renal disease. ${ }^{3}$ It has been observed to occur primarily in patients receiving maintenance hemodialysis and peritoneal dialysis. However, syndromes resembling calciphylaxis have been reported in individuals with pre-end-stage renal disease-staged CKD and even more rarely in those without any evidence of renal dysfunction but with inflammatory bowel disease, malignancy, trauma, and primary hyperparathyroidism. ${ }^{4-7}$

This disease entity is characterized by calcification, intimal hypertrophy, and thrombosis of small vessels that slowly lead to tissue ischemia followed by infarction. Predominantly affecting subcutaneous tissue, this microvasculopathic 
process leads to the formation of painful nodules or plaques, which are often described as erythematous or violaceous foci that later erupt as necrotizing, nonhealing ulcers. These lesions are typically distributed in highly vascular regions with thick overlying adipose tissue such as the breast, abdomen, and thighs, although acral and even visceral organ involvement has been reported. ${ }^{4}$ The formation of these ulcerating necrotic lesions portends a grim prognosis as they are often accompanied by severe infectious complications resulting in mortality rates that can exceed $60 \%{ }^{3,8}$

Several strategies aimed at treating and preventing this affliction in the nondialysis population have been reported in the literature. These include early parathyroidectomy, ${ }^{5,7}$ sodium thiosulfate, ${ }^{8,9}$ vitamin D analogs, ${ }^{9}$ bisphosphonates, ${ }^{10}$ cinacalcet, ${ }^{10,11}$ and hyperbaric oxygen. ${ }^{12}$ Unfortunately, none of these maneuvers have been shown to be universally beneficial and the outcome for most patients afflicted with calciphylaxis remains quite poor.

We describe a unique case of a patient with stage 3 CKD who presented with calciphylaxis when she developed primary hyperparathyroidism superimposed on background SHPT that was actively being treated with paricalcitol. She developed her lesions in the face of escalating dosages of the vitamin $\mathrm{D}$ analog despite normal $\mathrm{Ca}^{2+} \times \mathrm{PO}_{4}{ }^{2-}$ solubility products. What is interesting in this case is that her wounds did not begin to heal until her parathyroid adenoma was surgically removed and did not completely heal until her PTH level was normalized with cinacalcet.

PTH disrupts calcium homeostasis. In primary disease this is demonstrated in a straightforward way as PTH is secreted in a constitutive fashion from the parathyroid cells without regard for ambient serum calcium levels, often driving the remaining parathyroid glands into dormancy in the process. Hypercalcemia and/or high $\mathrm{Ca}^{2+} \times \mathrm{PO}_{4}^{2-}$ solubility products subsequently develop. In secondary disease the pathway is more complex.

In $\mathrm{CKD}$, the kidney has a decreased ability to generate 1,25-dihydroxycholecalciferol (calcitriol) from its precursor ergocalciferol via the kidney $25(\mathrm{OH}) 1-\alpha$-hydroxylase enzyme. Phosphate retention gradually occurs and this, in conjunction with reduced calcitriol levels, results in reduced intestinal calcium absorption and decreased serum calcium levels. As the degree of CKD progresses, the cellular expression of vitamin $\mathrm{D}$ receptors and calcium-sensing receptors (CaSRs) decrease within the parathyroid cells. Furthermore, the CaSRs are less sensitized to ambient calcium levels. ${ }^{13,14}$ These circumstances eventually lead to an increase in PTH release and a resultant rise in calcium levels. In the long-term, this phenomenon is maladaptive as it leads to bone demineralization (renal osteodystrophy). In these scenarios, PTH is believed by some investigators to enhance coronary artery calcification $\mathrm{s}^{15}$ and lead to the aforementioned microvascular calcification, intimal hypertrophy, and thrombosis, which in turn leads to ischemia and subsequent calciphylactic ulcers. ${ }^{16}$ More recently, fibroblast growth factor 23 (FGF-23) has been established as an important player in the regulation of phosphate-vitamin D homeostasis. FGF-23 concentration increases in CKD and contributes to the development of SHPT. Elevations in FGF-23 expression lead to the downregulation of residual renal $25(\mathrm{OH}) 1-\alpha$-hydroxylase enzyme activity. This unfortunately potentiates the previously mentioned deficiency of calcitriol production, resulting in enhanced PTH synthesis and subsequent parathyroid hyperplasia. ${ }^{17}$

In our patient, both pathways were operating concurrently. It also explains why she had an excellent initial response to a surgical intervention in the form of a subtotal parathyroidectomy. As the parathyroid adenoma was removed, her PTH levels fell. However, it was not until the calcimimetic agent cinacalcet was added that the PTH level normalized followed by complete wound healing. Calcimimetic agents activate the CaSRs, thereby potentiating the effects of ambient extracellular calcium on parathyroid cell function. ${ }^{18}$ This, in effect, reengages a negative feedback loop and suppresses PTH secretion. Calcimimetics also upregulate CaSR- and vitamin D-receptor expression and, in animal models, reduce parathyroid gland hypertrophy. ${ }^{19}$ In our patient, the use of cinacalcet allowed us to lower her secondary elevations in PTH without having to provide her with calcitriol or vitamin D analogs, which theoretically may have worsened her calciphylaxis.

In conclusion, calciphylaxis is a disabling and potentially life-threatening complication most often accompanying advanced degrees of renal insufficiency. A variety of interventions have been proposed to treat and/or prevent this morbid condition; unfortunately, the outcome for most patients afflicted with calciphylaxis remains poor. To the best of our knowledge, this case represents the first reported case of an individual with stage $3 \mathrm{CKD}$ who developed calciphylaxis amidst mixed hyperparathyroidism (both primary and secondary) and was successfully treated with subtotal parathyroidectomy (for pathologically confirmed parathyroid adenoma) followed by cinacalcet (for background SHPT). We feel this case is extraordinary because of the patient's development of calciphylaxis in spite of her relatively mild stage of CKD, as well as clinical response to specific therapy targeted at the pathophysiology of both primary and SHPT as detailed. Based on our experience in conjunction 
with that reported by others, we feel that administration of calcimimetics should be considered as an important adjunct in the treatment of calciphylaxis.

\section{Authors' contributions}

$\mathrm{MB}$ : direct patient care, article conception, literature search, case review and summary, drafting of the original article. AH: direct patient care, critical review. All authors read and approved the final manuscript.

\section{Acknowledgments}

Written consent was obtained from the patient for publication of this study. The authors would like to thank Dr Ruth Hanno for her critical review and interpretation of the dermatopathology slides and Dr George Pavlidakey for his excellent dermatologic care and advice.

\section{Disclosure}

The authors declare that they have no competing interests in this work.

\section{References}

1. Fine A, Zacharias J. Calciphylaxis is usually non-ulcerating: risk factors, outcome and therapy. Kidney Int. 2002;61(6):2210-2217.

2. Soni $\mathrm{S}$, Leslie WD. Bone scan findings in metastatic calcification from calciphylaxis. Clin Nucl Med. 2008;33(7):502-504.

3. Budisavljevic MN, Cheek D, Ploth DW. Calciphylaxis in chronic renal failure. JAm Soc Nephrology. 1996;7(7):978-982.

4. Wilmer WA, Magro CM. Calciphylaxis: Emerging concepts in prevention, diagnosis, and treatment. Semin Dial. 2002;15(3):172-186.

5. Kane WJ, Petty PM, Sterioff S, McCarthy JT, Crotty TB. The uremic gangrene syndrome: improved healing in spontaneously forming wounds following subtotal parathyroidectomy. Plast Reconstr Surg. 1996;98(4):671-678.

6. Llach F. The evolving clinical features of calciphylaxis. Kidney Int Suppl. 2003;(85):S122-S124.
7. Bishop J, Bown E, Podesta A, Troy C, Dong X. Surgical management of calciphylaxis associated with primary hyperparathyroidism: a case report and review of the literature. Int J Endocrinol. 2010;2010:823210.

8. Brucculeri M, Cheigh J, Bauer G, Serur D. Long-term intravenous sodium thiosulfate in the treatment of a patient with calciphylaxis. Semin Dial. 2005;18(5):431-434.

9. Kyritsis I, Gombou A, Griveas I, Agroyannis I, Retsa K, Agroyannis B. Combination of sodium thiosulphate, cinacalcet, and paricalcitol in the treatment of calciphylaxis with hyperparathyroidism. Int J Artif Organs. 2008;31(8):742-744.

10. Monney P, Nguyen QV, Perroud H, Descombes E. Rapid improvement of calciphylaxis after intravenous pamidronate therapy in a patient with chronic renal failure. Nephrol Dial Transplant. 2004;19(8): 2130-2132.

11. Mohammed IA, Sekar V, Bubtana AJ, Mitra S, Hutchinson AJ. Proximal calciphylaxis treated with calcimimetic 'Cinacalcet'. Nephrol Dial Transplant. 2008;23(1):387-389.

12. Podymow T, Wherrett C, Burns KD. Hyperbaric oxygen in the treatment of calciphylaxis: a case series. Nephrol Dial Transplant. 2001;16(11):2176-2180.

13. Fukuda N, Tanaka H, Tominaga Y, Fukagawa M, Kurokawa K, Seino Y. Decreased 1,25-dihydroxyvitamin D3 receptor density is associated with a more severe form of parathyroid hyperplasia in chronic uremic patients. J Clin Invest. 1993;92(3):1436-1443.

14. Gogusev J, Duchambon P, Hory B, et al. Depressed expression of calcium receptor in parathyroid gland tissue of patients with primary or secondary uremic hyperparathyroidism. Kidney Int. 1997; 51(1):328-336.

15. Coen G, Manni M, Mantella D, et al. Are PTH serum levels predictive of coronary calcifications in haemodialysis patients? Nephrol Dial Transplant. 2007;22(11):3262-3267.

16. Smiley CM, Hanlon SU, Michel DM. Calciphylaxis in moderate renal insufficiency: changing disease concepts. Am J Nephrol. 2000;20(4):324-328.

17. Cunningham J, Locatelli F, Rodriguez M. Secondary hyperparathyroidism: pathogenesis, disease progression, and therapeutic options. Clin J Am Soc Nephrol. 2011;6(4):913-921.

18. Nagano N. Pharmacological and clinical properties of calcimimetics: calcium receptor activators that afford an innovative approach to controlling hyperparathyroidism. Pharmacol Ther. 2006;109(3): 339-365.

19. Stubbs JR, Wetmore JB. Does it matter how parathyroid hormone levels are suppressed in secondary hyperparathyroidism? Semin Dial. 2011;24(3):298-306.

\section{Publish your work in this journal}

The International Journal of Nephrology and Renovascular Disease is an international, peer-reviewed open-access journal focusing on the pathophysiology of the kidney and vascular supply. Epidemiology, screening, diagnosis, and treatment interventions are covered as well as basic science, biochemical and immunological studies. The journal welcomes original research, clinical studies, reviews \& evaluations, expert opinion and commentary, case reports and extended reports. The manuscript management system is completely online and includes a very quick and fair peerreview system, which is all easy to use. Visit http://www.dovepress.com/ testimonials.php to read real quotes from published authors. 